\title{
Optical properties of ion assisted deposited zirconia thin films
}

\author{
M. Ghanashyam Krishna, K. Narasimha Rao, and S. Mohan \\ Instrumentation and Services Unit. Indian Institute of Science, Bangalore 560 012, India
}

\begin{abstract}
The nature of the dependence of refractive index, extinction coefficient, and packing density of zirconia films prepared by ion assisted deposition on the energy and current density of ions has been investigated. A broad beam Kaufman ion source has been used to generate oxygen ions in the energy range $100-700 \mathrm{eV}$ and current densities up to $220 \mathrm{uA} / \mathrm{cm} 2$. It has been found that the refractive index increases steadily up to an energy of $500 \mathrm{eV}$ beyond which there is a nominal decrease. The highest index obtained was 2.21 at an energy of $500 \mathrm{eV}$ and a current density of $220 \mathrm{uA} / \mathrm{cm} 2$. Similarly, with an increase in the current density the refractive index increases initially and seems to saturate beyond a certain critical value dependent on the ion energy. The extinction coefficient was low up to an energy of $300 \mathrm{eV}$ showing a marked increase thereafter. The extinction coefficient was also found to increase at high ion current densities and energies. A critical ion energy and current density beyond which the refractive index as well as the extinction coefficient of these films start deteriorating has been observed.
\end{abstract}

\section{INTRODUCTION}

The effect of ion bombardment on growing films has been the subject of many reviews in the recent past.'-' Ion bombardment can be used to control a variety of properties of the thin films like refractive index, absorption, scattering, stress, hardness, microstructure, structure, thermal conductivity, etc. The main motivation behind the work on optical coatings has been to prepare films with bulklike properties. The deviation of optical properties of the films from the corresponding bulk material is a consequence of the microstructure of the films. The microstructure of the films deposited by conventional physical vapor deposition (PVD) techniques is columnar which results in lower packing density and hence lower refractive index in these films. It has been found that ion bombardment of the films during deposition significantly reduces the columnar character of the films. This occurs due to the energy imparted by the ions to the adatoms increasing their mobilities, as well as reactivity in the case of reactive ion beam deposition. Some of the techniques that commonly use ions are activated reactive evaporation, ion plating, ion assisted deposition and ion beam sputtering. The latter two techniques are the most commonly used ones for producing high quality optical coatings.

Zirconia is considered a good material for optical coatings because of its fairly high refractive index (2.21 at 600 $\mathrm{nm}$ ) and low absorption. It has been deposited by a wide range of techniques like e $\mathrm{v}$ a p rat i o nsputtering, 10y lion plating,I2 pulsed laser dep sition'etc. But most of these techniques result in films with either crystalline or optical inhomogeneity. Although there are some reports on the optical properties of ion assisted deposited ${ }^{14-16}$ and ion beam sputtered" zirconia films, very few systematic studies of the variation in the refractive index and optical extinction coefficient with ion energy and current density have been reported to the best of the present workers knowledge.

Previous work by the present $\mathrm{a} \sim$ th or s ' föctlsed on the optical properties of zirconia films deposited in neutral and low energy oxygen ions produced from a Heitmann type discharge source. This article presents a systematic study of the variation in these properties with ion energy and ion current density using a Kaufman ion source,

\section{EXPERIMENTAL}

The films were coated in an oil diffusion pumped chamber which could routinely give pressures of the order of $1 \times 10^{6}$ Torr. The starting material $\mathrm{ZrO}$, (99\% purity) was evaporated from a $6 \mathrm{~kW}$ electron beam gun (Leybold, Germany, model ESV6). The oxygen backfilling pressure was $2 \times 10^{-4}$ Torr during deposition. Fused silica substrates were placed at a distance of $25 \mathrm{~cm}$ above the source on a stationary workholder. The rate of deposition was maintained at $0.2 \mathrm{~nm} / \mathrm{s}$ using a home built quartz crystal monitor and films were coated to a nominal thickness of $200 \mathrm{~nm}$. A $3 \mathrm{~cm}$ broad beam ion source (Commonwealth ScientificCorp.) was used to generate oxygen ions. The ion energy could be varied from 100 to $1500 \mathrm{eV}$ and a maximum beam current of $175 \mathrm{~mA}$ at the source could be obtained. The discharge voltage was around $52 \mathrm{~V}$. The source had a hot cathode (tungsten) filament and the ion current could be varied by varying the filament current. The maximum life in reactive gas atmosphere was $3 \mathrm{~h}$. There were two collimated grids, accelerator and screen, which were made of graphite. A Faraday cup supplied by the company was used to monitor the current density at the substrate level. The ion source substrate distance was $28 \mathrm{~cm}$ and the angle of inclination to the substrate was $-20 "$. The experiments in this study were not performed at energies above $700 \mathrm{eV}$ due to the drastic increase in extinction coefficient at this energy. A schematic view of the experimentalchamber is shown in Fig. 1.

The spectral transmittance and near normal reflectance were measured in a Hitachi (Model No. 330) spectrophotometer in the range $200-1500 \mathrm{~nm}$. The refractive index and extinction coefficient were calculated from the transmittance data using the envelope technique developed by Swanpoel.*' Figure 2(a) shows a typical envelope drawn to 


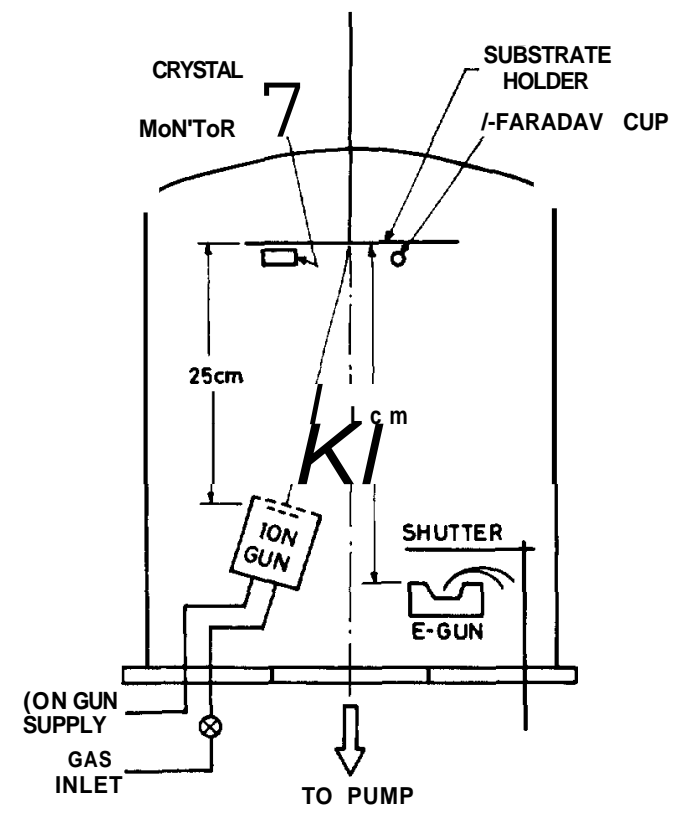

FIG. 1. A schematic view of the experimental chamber used in this study.

calculate the optical constants of the film represented in curve 1 . In this technique the optical losses due to scattering are assumed to be negligible and hence they have not been taken into account. Packing density was calculated using the Bragg and Pippard model modified by Harris et a1.21,2\&s reported earlier by Martin et a1.I4 the Bragg and Pippard model gives the most reasonable values for the packing density of zirconia films and hence it has been used in the present work.

The formula for packing density $(p)$ is

$$
\begin{aligned}
n_{f}^{2}= & {\left[(1-p) n_{v}^{4}+(1+p) n_{v}^{2} n_{S}^{2}\right] /\left[(1+p) n_{v}^{2}\right.} \\
& \left.+(1-p) n_{S}^{2}\right],
\end{aligned}
$$

where $n f=$ the refractive index of the film at the given wavelength, $p=$ the packing density, $n,=$ the index of the voids $=1$ for air $=1.33$ for water vapor, $n s=$ bulk value of refractive index $=2.21$ at $600 \mathrm{~nm}$.

\section{RESULTS AND DISCUSSION}

The measured spectral transmittance for the films deposited at $300 \mathrm{eV}$ ion energy and ion current density of 100 $\mathrm{pA} / \mathrm{cm} 2$ and $500 \mathrm{eV}$ energy and 100 and $220 \mathrm{pA} / \mathrm{cm} 2$ current density are shown in Fig. 2(a). From Fig. 2(a) it is seen that as the current densities are increased at a fixed ion energy and the energy is increased at a fixed ion current density the difference in transmittance extrema increases indicating an increase in refractive index. The absorption edge for these films is between 230 and $250 \mathrm{~nm}$ indicating nearly stoichiometric films. Figure 2(b) shows the deviation in transmittance of the coated substrate ( $\boldsymbol{T} \boldsymbol{f}$ ) from the uncoated substrate value $(\boldsymbol{T} \boldsymbol{s})$ as calculated from the envelope drawn to determine the refractive index and extinction coefficient. It is seen from Fig. 2(b) that with increasing energy at a fixed current density of $50 \mathrm{pA} / \mathrm{cm} 2$ the
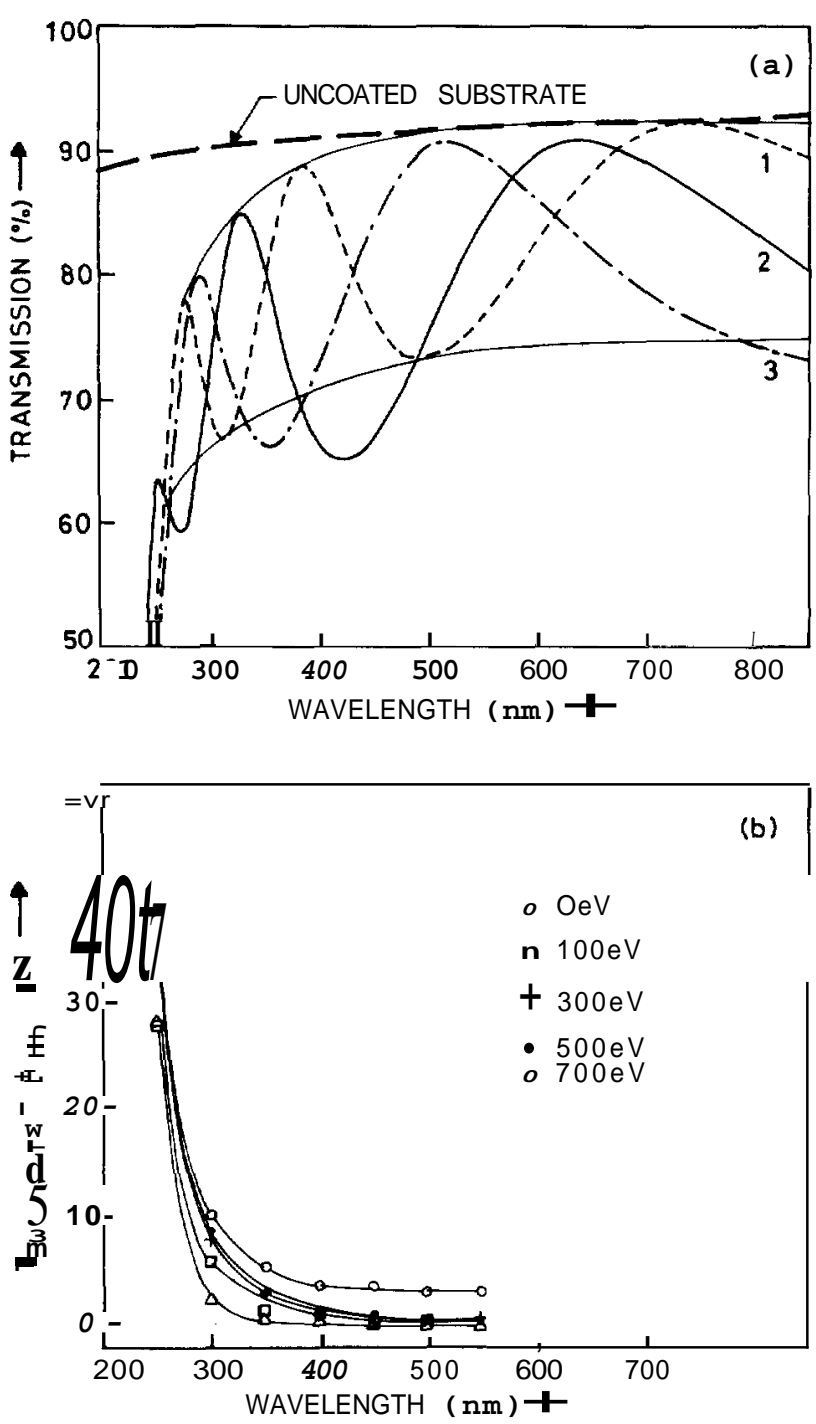

Fig. 2. (a) Measured spectral transmittance curves for the films deposited at (1) $300 \mathrm{eV}$ energy and $100 \mathrm{pA} / \mathrm{cm} 2$ current density, (2) $500 \mathrm{eV}$ energy and $100 \mathrm{pA} / \mathrm{cm} 2$ current density, (3) $500 \mathrm{eV}$ energy and 220 pA/cm2 current density; (b) The deviation in film transmittance (TfiI,) from substrate transmittance (Tsubstr\&be)the films. The $100 \mathrm{eV}$ film was deposited at $10 \mathrm{pA} / \mathrm{cm} 2$ while the other films were deposited at 50 $\mathbf{p A} / \mathrm{cm} 2$.

deviation from substrate transmittance increases with increasing energy at any wavelength. At energies $<300 \mathrm{eV}$ the film transmittance approaches that of the substrate transmittance even at wavelengths less than $400 \mathrm{~nm}$. This indicates lower extinction coefficient for these films.

The dispersion curves for films deposited at ion energies of 300 and $500 \mathrm{eV}$ and different current densities in the range $25-220 \mathrm{pA} / \mathrm{cm} 2$ are shown in Figs. 3(a) and 3(b). It is observed that at $300 \mathrm{eV}$ the change in index from 1.98 at $25 \mathrm{pA} / \mathrm{cm} 2$ to 2.10 at $220 \mathrm{pA} / \mathrm{cm} 2$ is not as pronounced as in the case of the films deposited at an energy of $500 \mathrm{eV}$ where the change was from 1.98 to 2.21 over the same range of current densities. The films deposited at a current density of $25 \mathrm{pA} / \mathrm{cm} 2$ show the same index of 1.98 at a wavelength of $600 \mathrm{~nm}$ at both 300 and $500 \mathrm{eV}$. The divergence begins at $50 \mathrm{pA} / \mathrm{cm} 2$ where the $300 \mathrm{eV}$ films show an index of 2.00 while the $500 \mathrm{eV}$ film shows an index of 2.14 . 


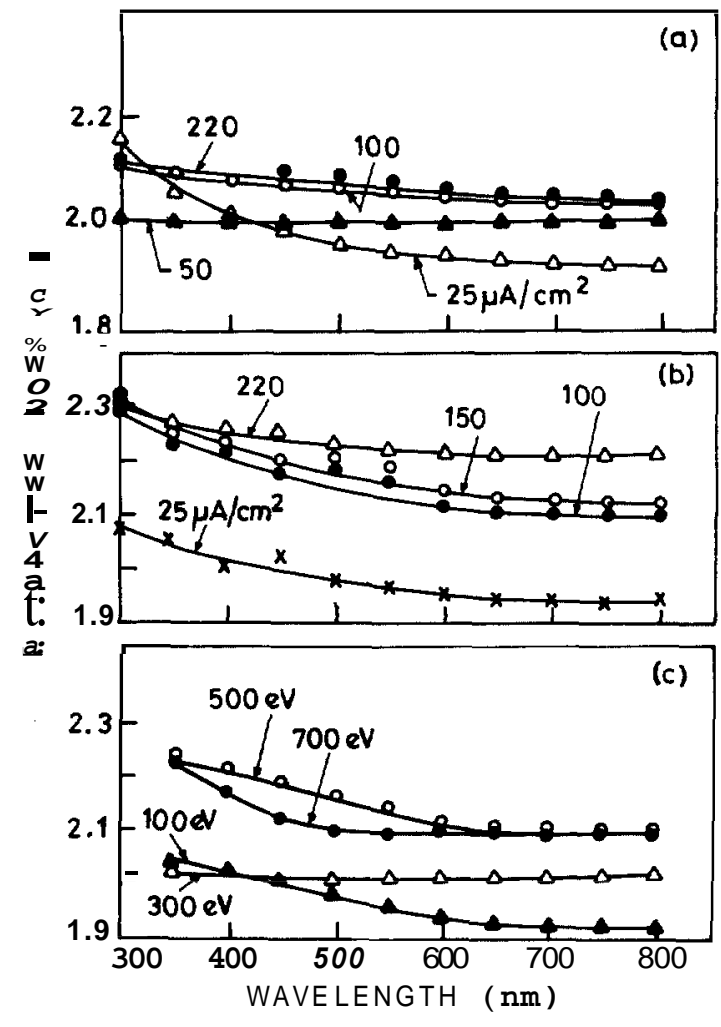

FIG. 3. The dispersion curves for the films (a) deposited at an energy of $300 \mathrm{eV}$ and different current densities (b) deposited at an energy of 500 $\mathrm{eV}$ and different current densities (c) deposited at $50 \mathrm{pA} / \mathrm{cm} 2$ current density and different energies. The film at $100 \mathrm{eV}$ was deposited at a current density of $10 \mathrm{pA} / \mathrm{cm} 2$.

The refractive index of the films deposited at $300 \mathrm{eV}$ seems to saturate immediately thereafter whereas that for the 500 $\mathrm{eV}$ films shows a gradual increase reaching a maximum at $220 \mathrm{pA} / \mathrm{cm} 2$. Figure 3(c) shows the dispersion in refractive index for the films deposited at ion energies of 300 , 500 , and $700 \mathrm{eV}$ and a current density of $50 \mathrm{pA} / \mathrm{cm} 2$ and that for the $100 \mathrm{eV}$ film which was deposited at 10 $\mathrm{pA} / \mathrm{cm} 2$. It was observed that the value of refractive index, 1.94 , at $600 \mathrm{~nm}$ for the film deposited at $100 \mathrm{eV}$ using the Kaufman source is higher than the highest value, 1.9, at $600 \mathrm{~nm}$ obtained by using the Heitmann type discharge $\sim 0$ urce. The index increases steadily with increase in ion energy reaching a maximum at $500 \mathrm{eV}$. At $700 \mathrm{eV}$ there is a slight decrease in the refractive index value. It increases from 1.94 at $100 \mathrm{eV}$ and $10 \mathrm{pA} / \mathrm{cm} 2$ current density to 2.15 at $500 \mathrm{eV}$ and then reduces to 2.12 at $700 \mathrm{eV}$ at a current density of $50 \mathrm{pA} / \mathrm{cm} 2$ and wavelength of $600 \mathrm{~nm}$. The initial increase in refractive index up to an energy of 500 $\mathrm{eV}$ can be attributed to the increase in packing density with increasing energy and improved oxidation due to enhanced reactivity in the presence of ions.

Figures 4(a) and 4(b) show the variation in packing density as a function of current density for films deposited at ion energies of 300 and $500 \mathrm{eV}$. In the expression for the calculation of packing density, $n$, is the refractive index of the voids, which can either be assumed to be saturated with water vapor or filled with air. It is observed from Figs.

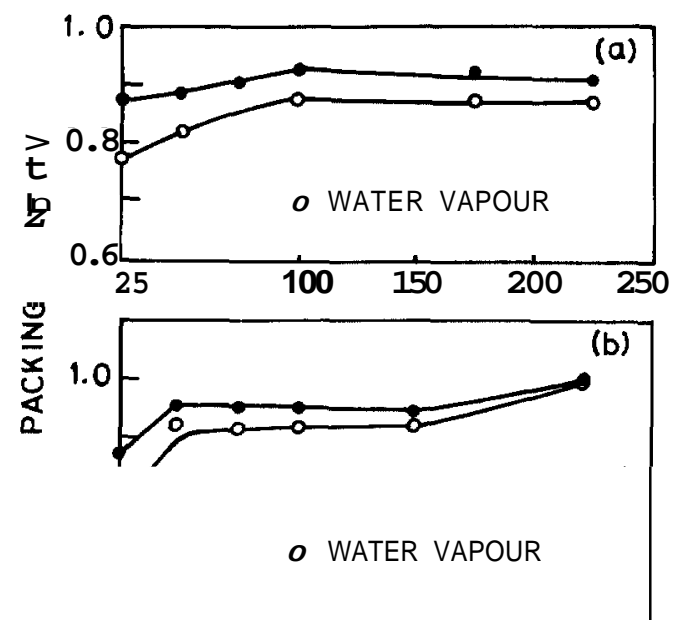

4(a) and 4(b) that the former assumption leads to (1) a lower packing density for the films and (2) that as long as the packing density is less than 0.9 there is large divergence in the values obtained from the two assumptions. In the absence of in situ measurements of refractive index this can be taken as a good measure of the presence of moisture adsorption in the films. It can be further observed from these figures that at $300 \mathrm{eV}$ the two curves start approaching each other at a current density of $100 \mathrm{pA} / \mathrm{cm} 2$ whereas at $500 \mathrm{eV}$ they do so at a lower current density of $\mathbf{5 0}$ $\mathrm{pA} / \mathrm{cm} 2$. This indicates that the films deposited at the higher energy adsorb less moisture. It can also be seen that the films deposited at $500 \mathrm{eV}$ have a higher packing density than those deposited at $300 \mathrm{eV}$. It can thus be stated that the films deposited under the influence of ion bombardment have high packing density and therefore adsorb very little moisture.

The variation in extinction coefficient $(\boldsymbol{k})$ of the films with wavelength is plotted in Figs. 5(a)-5(c). Figures 5 (a) and 5 (b) show the variation in $\mathrm{k}$ for the films deposited at $300 \mathrm{eV}$ and current densities of 25, 50, 100, and 220 $\mathrm{pA} / \mathrm{cm} 2$ and $500 \mathrm{eV}$ and current densities of 25, 100, 150, and $220 \mathrm{pA} / \mathrm{cm} 2$, respectively. From these figures it is observed that films deposited at current densities up to 100 $\mathrm{pA} / \mathrm{cm} 2$ show low extinction coefficient for the $300 \mathrm{eV}$ case whereas it is low up to $150 \mathrm{pA} / \mathrm{cm} 2$ at $500 \mathrm{eV}$ with a drastic increase in extinction thereafter in both cases. Figure 5(c) shows the films deposited at $50 \mathrm{pA} / \mathrm{cm} 2$ current density and energies of 300,500 , and $700 \mathrm{eV}$. Also shown is the $100 \mathrm{eV}$ film which was deposited at $10 \mathrm{pA} / \mathrm{cm} 2$. It is observed that the extinction coefficient of the films deposited at energies less than $500 \mathrm{eV}$ is much lower compared to the films deposited at $700 \mathrm{eV}$. At $700 \mathrm{eV}$ there is drastic increase in the extinction coefficient, increasing from 0.002 at $100 \mathrm{eV}$ to 0.0085 for $700 \mathrm{eV}$ at a wavelength of $600 \mathrm{~nm}$. These values are slightly higher than the $6.5 \times 10^{-4}$ reported by Martin et al. 14 but are of the same order as those 


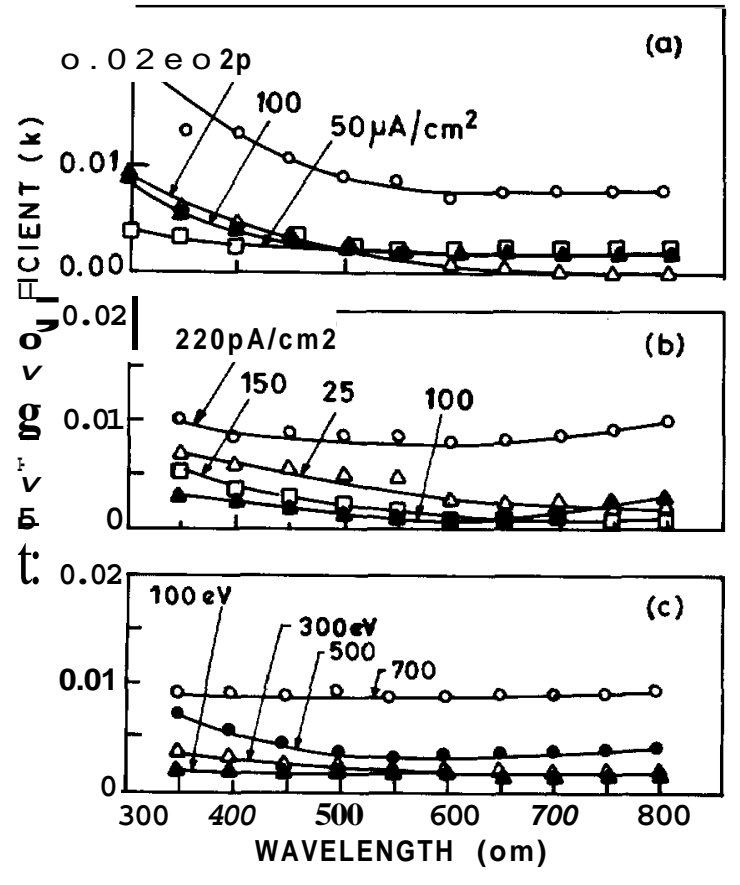

FIg. 5. The variation in extinction coefficient with wavelength for the films (a) deposited at an energy of $300 \mathrm{eV}$ and different current densities (b) deposited at an energy of $500 \mathrm{eV}$ and different current densities (c) deposited at $50 \mathrm{pA} / \mathrm{cm} 2$ current density and different energies. The film at $100 \mathrm{eV}$ was deposited at a current density of $10 \mathrm{pA} / \mathrm{cm} 2$.

reported by Rujkorakarn and Sites for ion beam sputtered fiims. 17

Figure 6(a) shows the variation in refractive index with ion current density which has also been expressed in terms
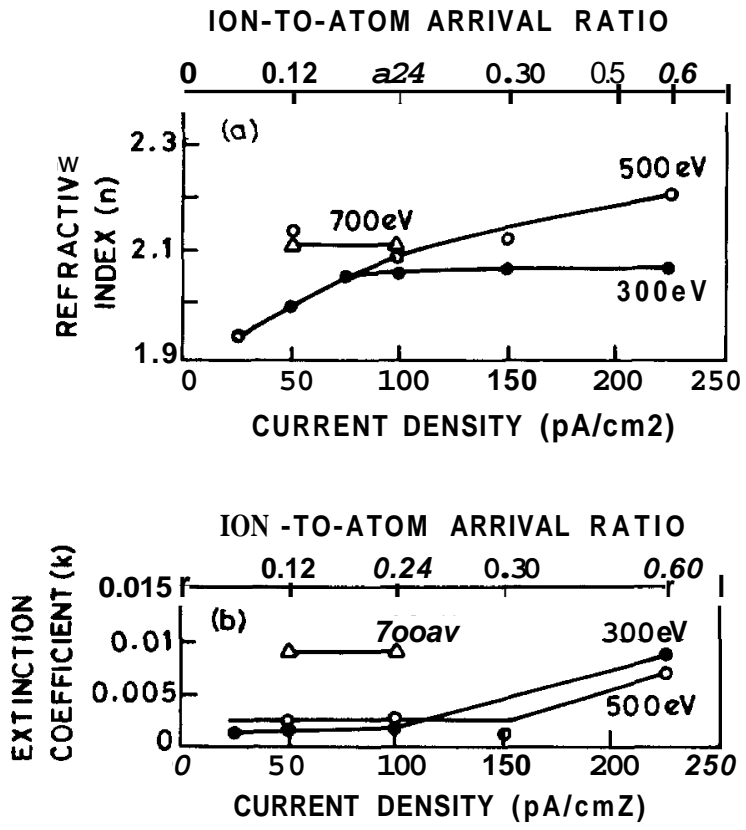

FIG. 6. (a) The variation in refractive index with current density for the films deposited at ion energies of 300,500 , and $700 \mathrm{eV}$. (b) The variation in extinction coefficient with current density at $600 \mathrm{~nm}$ for the films deposited at 300, 500, and $700 \mathrm{eV}$. of the ion to (vapor) atom arrival ratio for different energies at a wavelength of $600 \mathrm{~nm}$. It is seen that with increasing arrival ratio the refractive index gradually increases for arrival ratios up to $0.24(100 \mathrm{pA} / \mathrm{cmZ})$ remaining constant thereafter up to arrival ratios of 0.6 for $300 \mathrm{eV}$ and for 500 $\mathrm{eV}$ the saturation is more gradual. At $700 \mathrm{eV}$ the film index remains invariant up to an arrival ratio of 0.24 (100 $\mathrm{pA} / \mathrm{cm} 2$ ). This kind of behavior in index with increasing current density at a fixed ion energy has also been reported by Martin et al.14 for zirconia films deposited at $600 \mathrm{eV}$ and current density up to $200 \mathrm{pA} / \mathrm{cm} 2$.

The highest value 2.21 was obtained at an energy of 500 $\mathrm{eV}$ and ion current density of $220 \mathrm{pA} / \mathrm{cm} 2$. This compares very favorably with the values of 2.19 for the ambient temperature and 2.23 for the 300 "C deposited films reported by Martin et $\boldsymbol{a L l 4}$ for ion assisted deposited films at an energy of $600 \mathrm{eV}$ and current density of $200 \mathrm{pA} / \mathrm{cm} 2$. Values of 2.2 have also been reported for ion beam sputtered films.17 The increase in refractive index with energy in ion assisted deposition has been reported by $\mathrm{M} \sim \mathrm{Nally}$, for TazO, films in the energy range $200-500 \mathrm{eV}$, Alz03in the range $300-1000 \mathrm{eV}$ and Netterfield et al.24 for CeOzfilms in the energy range 300-1200 eV.

Figure 6(b) shows the variation in extinction coefficient (k) at ion energies of 300,500 , and $700 \mathrm{eV}$ as a function of current density at a wavelength of $600 \mathrm{~nm}$. At $300 \mathrm{eV}$ the $\boldsymbol{k}$ value of the films seems to be low up to $100 \mathrm{pA} / \mathrm{cm} 2$ and increases beyond that. At $500 \mathrm{eV}$ the increase in $\boldsymbol{k}$ values starts at a value of $150, \mathrm{uA} / \mathrm{cm} 2$. At $700 \mathrm{eV}$ the $\boldsymbol{k}$ value is uniformly high irrespective of the current density.

Al-Jumaily et $\boldsymbol{a L Z S h a v e ~ e a r l i e r ~ r e p o r t e d ~ a n ~ i n c r e a s e ~ i n ~}$ tungsten contamination of the films at high levels of ion bombardment in titania films and have mentioned this as a possible cause for increase in extinction coefficient at higher values of current density. McNallyZ3has also reported an increase in extinction coefficient beyond $300 \mathrm{eV}$ for Ta2O5films and Netterfield et $\boldsymbol{a L Z 4 h a v e ~ s e e n ~ a n ~ i n - ~}$ crease in extinction coefficient in $\mathrm{CeO}$, films beyond 600 $\mathrm{eV}$. It should be mentioned here that Auger depth profiling done on the high extinction coefficient films in the present work did not reveal any tungsten. This eliminates the possibility of increase in $\boldsymbol{k}$ values due to film contamination by tungsten from the ion source filament and indicates that preferential sputtering of oxygen is the most probable mechanism for the increase in extinction coefficient at higher levels of bombardment.

The above discussion clearly indicates the presence of a critical value of energy at a fixed ion current density and vice versa, beyond which the refractive index and extinction coefficient behavior starts deteriorating.

The existence of a critical energy at a fixed ion current density and a critical current density at a fixed energy beyond which both the refractive index and the extinction coefficient start deteriorating has also been observed in Ta2O5, A1203,2 Ce02,24and titania films26as also in zirconia films deposited at a fixed ion energy.14 This behavior has been attributed to the degradation of film stoichiometry due to preferential sputtering or excess oxygen incorporation in the films beyond the critical value. Muller in 
his models on ion assisted deposition has also referred to this process as being the cause for deterioration in optical properties at higher levels of ion bombardment.*' Although, here the refractive index seems to saturate, the extinction coefficient increases by a large magnitude beyond the critical value. In a study done on ceria films by Netterfield $\boldsymbol{e t} \boldsymbol{a l . 2 4}$ at an energy of $1200 \mathrm{eV}$ it was found that the stoichiometry approached the required oxygen to metal ratio, i.e., 2 up to a certain current density, while above and below this value there were large deviations in stoichiometry. This resulted in a decrease in refractive index and an increase in extinction coefficient at points away from the critical value. This would indicate that the films in the present case are most stoichiometric at the critical value. The $\mathrm{x}$-ray diffraction patterns revealed that all films were X-ray amorphous. Martin et al.,I4 have reported the formation of as deposited crystalline films in their work. The possible causes for this difference in behavior could be twofold. The films in that study were deposited at a higher rate, 0.8 as against $0.2 \mathrm{~nm} / \mathrm{s}$, and to greater total thicknesses than in the present study.

\section{CONCLUSIONS}

Thin films of zirconia have been deposited using ion assisted deposition. It has been found that the refractive index increases steadily with an increase in ion energy and current. There is a marked increase in packing density with increasing ion energy. The extinction coefficient of these films is lower at energies below $300 \mathrm{eV}$ than at higher energies. The existence of a critical value of ion energy and current density beyond which the refractive index and extinction coefficient deteriorate has been observed.

'P. J. Martin, Vacuum 36, 585 (1986).

'F. A. Smidt, Int. Mater. Rev. 35, 61 (1990).

'J. M. E. Harper, J. J. Cuomo, R. J. Gambino, and H. R. Kaufman,
Nucl. Instrum. Methods B 7, 886 (1985).

4U. J. Gibson, Physics of Thin Films, wited by M. Francombe and J. L. Vossen (Academic, New York, 1987), Vol. XIIL, pp. 109-150.

'P. J. Martin and R. P. Netterfield, in Progress in optics, edited by E. Wolf (North-Holland, Amsterdam, 1986), Vol. XXIII, pp. 115-183. 6K.V. S. R. Apparao, N. K. Sahoo, and T. C. Bagchi, Ind. J. Phys. 60A, 216 (1986).

'V. V. Klechkovskaya, V. I. Khitrova, S. 1. Sagitov, and S. A. Semiletov, Sov. Phys. Crystallogr. 25, 636 (1980).

'J. A. Dobrowolski, P. D. Grant, R.D. Simpson, and A. J. Waldorf, Appl. Opt. 28, 3997 (1989).

9R. E. Klinger, and C. K. Carniglia, Appl. Opt. 24, 3184 (1985).

W. T. Pawlewicz and D. D. Hays, Thin Solid Films 94, 31 (1982).

'IF. Jones, J. Vac. Sci. Technol. A 6, 3088 (1988).

12H.K. Pulker, M. Buehler, and R. Hora, Proceedings of the Society of Photo-Optical Instrument Engineering, Optical Thin Films 11-New Developments 1986 (unpublished), Vol. 678, p. 110.

"H. Sankur, J. DeNatale, W. Gunning, and J. Nelson, J. Vac. Sci. Technol. A 5, 2869 (1987).

"'P. J. Martin, P. Netterlield, and W. G. Sainty, J. Appl. Phys. 55, 235 (1984).

IP. J. Martin, H. A. Macleod, R. P. Netterlield, C. G. Pacey, and W. G. Sainty, Appl. Opt. 22, 178 (1983).

I6K. H. Muller, R. P. Nettdeld, and P. J. Martin, Phys. Rev. B 35, 2934 (1987).

"R. Rujkorakarn and J. R. Sites, J. Vac. Sci. Technol. A 4, 568 (1986). I'M. Ghanashyam Krishna, K. Narasimha Rao, and S. Mohan, Appl. Phys. Lett. 57, 557 (1990).

19M. Ghanashyam Krishna, K. Narasimha Rao, and S. Mohan, Thin Solid Films 193/194, 690 (1990).

OR. Swanepoel, J. Phys. E 16, 1214 (1983).

"W. L. Bragg, and A. B Pippard, Acta Crystallogr. 6, 865 (1953).

"M. Harris, H. A. Maclaod, S. Ogura, E. Pelletier, and B. Vidal, Thin Solid Films 57, 173 (1979).

*'J. J. McNally, Ph.D. thesis, University of New Mexico at Albuquerque, 1986.

24R.P. Nettertield, W. G. Sainty, P. J. Martin, and S. H. Sie, Appl. Opt. 24, 2267 (1985).

25G.A. Al-Jumaily, S. R. Wilson, A. C. Barron, J. R. McNeil, and B. L. Doyle, Nucl. Instrum. Methods B 7/8, 906 (1985).

26J.R. McNeil, A. C. Barron, S. R. Wilson, and W. C. Hermann, Jr., Appl. Opt. 23, 552 (1984).

"K. H. Muller, in Handbook of Ion Beam Processing Technology, edited by J. J. Cuomo, S. M. Rossnagel, and H. R. Kaufman (Noyes, Park Ridge, NJ, 1989), p. 241. 